\section{Commentary: Hybrid \\ valve-in-valve transcatheter mitral valve replacement: You can never have too many tools in your toolbox}

\author{
Gaetano Paone, MD, MHSA, ${ }^{\mathrm{a}}$ and \\ Adam B. Greenbaum, MD ${ }^{\mathrm{b}}$
}

Previous reports have described open on-pump placement of a balloon-expandable catheter valve in patients with severe mitral annular calcification..$^{1-3}$ In this issue of JTCVS Techniques, Harloff and colleagues ${ }^{4}$ have presented a similar hybrid approach to transcatheter mitral valve replacement (TMVR) in a high-risk patient with bioprosthetic valve failure and severe recurrent mitral stenosis. Preoperative computed tomography had revealed a neo-left ventricular outflow tract (LVOT) area of $0.46 \mathrm{~cm}^{2}$, placing the patient at high risk of LVOT obstruction with valve-invalve TMVR alone.

After median sternotomy with cardiopulmonary bypass and cardioplegic arrest, the mitral valve was exposed routinely through the left atrium. Rather than again replacing the valve, the authors excised the 2 bioprosthetic leaflets positioned anteriorly and, under direct vision, successfully deployed a Sapien 3 valve (Edwards LifeSciences, Irvine, Calif) inside the stent frame of the remaining prosthesis. The cross-clamp and bypass times were 35 and 60 minutes,

From the Divisions of ${ }^{\mathrm{a}}$ Cardiothoracic Surgery and ${ }^{\mathrm{b}}$ Cardiology, Structural Heart and Valve Center, Emory University School of Medicine, Atlanta, Ga.

Disclosures: Dr Paone is a consultant and proctor for Edwards LifeSciences and owns equity in Medtronic. Dr Greenbaum is a proctor for Edwards LifeSciences and Medtronic and a consultant for Transmural Systems; his employer has research contracts for clinical investigation of transcatheter aortic and mitral devices from Edwards LifeSciences, Abbott Vascular, Medtronic, St. Jude Medical, and Boston Scientific.

The Journal policy requires editors and reviewers to disclose conflicts of interest and to decline handling or reviewing manuscripts for which they may have a conflict of interest. The editors and reviewers of this article have no conflicts of interest.

Received for publication May 8, 2020; revisions received May 8, 2020; accepted for publication May 21, 2020; available ahead of print June 24, 2020.

Address for reprints: Gaetano Paone, MD, MHSA, Division of Cardiothoracic Surgery, Structural Heart and Valve Center, Emory University Midtown Hospital, Medical Office Tower, 6th Floor, 550 Peachtree St, NE, Atlanta, GA 30308 (E-mail: gpaone313@gmail.com).

JTCVS Techniques 2020;3:160-1

2666-2507

Copyright (c) 2020 The Authors. Published by Elsevier Inc. on behalf of The American Association for Thoracic Surgery. This is an open access article under the CC BY-NCND license (http://creativecommons.org/licenses/by-nc-nd/4.0/).

https://doi.org/10.1016/j.xjtc.2020.05.031

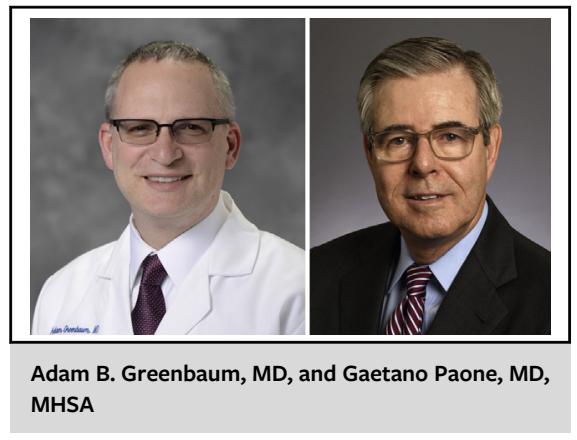

CENTRAL MESSAGE

As demonstrated by this hybrid approach to TMVR, the patient with complex structural heart disease is best treated by a multidisciplinary heart team with a broad range of technical expertise.

respectively. The patient did well with no perivalvular leakage and low mitral valve and LVOT gradients.

Fully catheter-based approaches to mitigate the risk of LVOT obstruction during TMVR are, in fact, available. Septal ablation can be performed before valve replacement but will require several weeks for its full effect and has a number of limitations. ${ }^{5}$ Laceration of the anterior mitral leaflet to prevent left ventricular outflow tract obstruction (LAMPOON) was first reported in patients at prohibitive surgical risk after previous mitral valve repair or with mitral annular calcification. ${ }^{6,7}$ More recently, a less technically demanding revision of this technique referred to as "tip-to-base" or "reverse" LAMPOON has been described for use in patients undergoing either valve-in-ring or valve-in-valve TMVR. ${ }^{8}$ Both techniques have effectively prevented LVOT obstruction after TMVR, albeit also with limitations.

The hybrid approach to valve-in-valve TMVR described by Harloff and colleagues ${ }^{4}$ ensures removal of potentially obstructing anterior leaflet tissue and should allow for more precise positioning of the transcatheter valve within the previous bioprosthesis. However, involving as it does sternotomy, cardiopulmonary bypass, and cardiac arrest, it comes at the cost of invasiveness, with its main advantage compared with repeat replacement a seemingly variable and undefined reduction in bypass and clamp times of uncertain clinical significance. Although minimizing the bypass time will always be desirable, it is, nonetheless, difficult to perceive this as a 
less-invasive approach suitable for routine use in higher risk patients for whom it seems particularly intended.

Given the lower overall incidence of LVOT obstruction during valve-in-valve TMVR compared with TMVR-insurgical rings and/or mitral annular calcification, ${ }^{9}$ it seems unlikely that this technique will find wide application. Nevertheless, the authors are to be congratulated for adding another approach to address LVOT obstruction in the occasional patient for whom no less-invasive catheter-based options are available, and for whom true repeat MVR is, for whatever reason, best avoided. ${ }^{4}$

The master artisan approaches their craft with all the tools possibly needed readily available in the toolbox from the outset. So too, the contemporary multidisciplinary heart team should collectively have available a broad range of technical expertise in the growing armamentarium of available surgical and nonsurgical approaches required to most safely confront these increasingly complex and challenging conditions.

\section{References}

1. Jain R, Algahim MF, Bajwa TK, Khandheria BK, O'Hair DP. Native mitral stenosis treated with transcatheter mitral valve replacement. Ann Thorac Surg. 2016;101:e75-7.
2. Praz F, Khalique OK, Lee R, Veeragandham R, Russell H, Guerrero M, et al Transatrial implantation of a transcatheter heart valve for severe mitral annular calcification. J Thorac Cardiovasc Surg. 2018;156:132-42.

3. Murashita T, Suri RM, Daly RC. Sapien XT transcatheter mitral valve replacement under direct vision in the setting of significant mitral annular calcification. Ann Thorac Surg. 2016;101:1171-4.

4. Harloff M, Papoy A, Aghayev A, Kaneko T. Hybrid valve-in-valve mitral valve replacement. J Thorac Cardiovasc Surg Tech. 2020;3:154-6.

5. Wang DD, Guerrero M, Eng MH, Eleid MF, Meduri CU, Rajagopal V, et al Alcohol septal ablation to prevent left ventricular outflow tract obstruction during transcatheter mitral valve replacement: first-in-man study. JACC Cardiovasc Interv. 2019;12:1268-79.

6. Babaliaros VC, Greenbaum AB, Khan JM, Rogers T, Wang DD, Eng $\mathrm{MH}$, et al. Intentional percutaneous laceration of the anterior mitral leaflet to prevent outflow obstruction during transcatheter mitral valve replacement: first-in-human experience. JACC Cardiovasc Interv. 2017; 10:798-809.

7. Khan JM, Babaliaros VC, Greenbaum AB, Foerst JR, Yazdani S, McCabe JM, et al. Anterior leaflet laceration to prevent ventricular outflow tract obstruction during transcatheter mitral valve replacement. J Am Coll Cardiol. 2019;73: 2521-34.

8. Case BC, Khan JM, Satler LF, Itsik BD, Lederman RJ, Babaliaros VC, et al. Tipto-base LAMPOON to prevent left ventricular obstruction in valve-in-valve transcatheter mitral valve replacement. JACC Cardiovasc Interv. 2020;13: 1126-8.

9. Eleid MF, Whisenant BK, Cabalka AK, Williams MR, Nejjari M, Attias D, et al. Early outcomes of percutaneous transvenous transseptal transcatheter valve implantation in failed bioprosthetic mitral valves, ring annuloplasty, and severe mitral annular calcification. JACC Cardiovasc Interv. 2017;10: 1932-42. 